\title{
A Evolução do Processo Decisório $e$ as Organizações
}

\section{Lahir Short de Azevedo}

\section{ESQUEMA DO TRABALHO}

CAPÍTULO I

\section{Introdução}

1. Considerações Gerais.

2. Explicação do Comportamento Humano nas Organizações.

3. O Equilibrio da Organização.

4. Sintese do Modêlo Decisório de Simon.

\section{CAPÍTULO II}

Exposição do pensamento de Simon

1. "Princípios de Administração."

2. Limites da Racionalidade.

3. Premissas Factuais e Premissas de Valor.

4. Comportamento Administrativo.

5. Tomada de Decisões no Processo Administrativo.

6. A Tomada de Decisões e sua Execução.

7. A Decisão sob o ponto-de-vista do indivíduo por ela responsável:

a) a gradação da influência;

b) modos e formas de influência organizativa.

8. Classificação de Cargos e Seleção.

9. Especialização.

10. Coordenação.

11. Comunicações.

12. Descentralização ou Centralização das Decisões? 


\section{CAPÍTULO III \\ Ajustamentos das Organizações ao Processo Decisório}

1. Planejamento.

2. Organização Formal e Organização Informal.

\section{CAPÍTULO IV}

Novas Perspectivas para as Organizações

Seção I - Processos Decisórios Programados e Não-Programados e suas consequiências mais imediatas.

Seção II - Modificações nas Organizações

a) Dimensão das Organizações;

b) Direção de Nivel Superior das Organizações;

c) Direção de Nivel Médio das Organizações;

d) Centralização das Decisões;

e) Perfil Ocupacional;

f) Estrutura das Organizações;

g) Organizações Públicas.

\section{CAPÍTULO I}

\section{INTRODUÇÃO}

\section{Considerações Gerais}

A multiplicidade e a universalidade das modernas organizasões, que constituem centros de atividades humanas grandemente diferenciadas, desde as empresariais, públicas ou privadas, até as educacionais, as recreativas e as totalmente voluntárias, refletem sua extrema importância no contexto da vida social, em que são propiciadoras de diuturnas inter-relações de milhões de pessoas.

No estudo do comportamento humano, envolvendo as influências que os individuos sofrem do meio ambiente e suas reaçoes, não pode deixar de inserir-se, assim, o comportamento organizacional, resultante de caracteristicas peculiares aos processos de influenciação adotados pelas organizações.

Essas caracteristicas se originam da coordenação de comportamentos organizacionais suscetiveis de ilustração através da aplicação do conceito sociológico do "papel" aos membros das organizações. Isto porque seus papéis tendem a ser muito minuciosos, relativamente estáveis e em grande parte definidos em têrmos ex- 
plícitos e até por escrito. Além de definidos para os indivíduos que os desempenham, são também conhecidos pelos integrantes da organização. $\left({ }^{*}\right)$

A existência dêsses papéis especificos faz com que o ambiente organizacional torne-se estável e previsivel, circunstância que, aliada a outros fatôres, permite às organizações agirem coordenadamente com o meio ambiente que as envolve. $\left({ }^{* *}\right)$

Como acentua Herbert Simon $\left({ }^{\star * *}\right)$, uma organização corresponde a um sistema de papéis, que proporciona a cada membro parte substancial das informações, pressupostos, objetivos e atitudes que entram nas suas decisões, propiciando-lhe, igualmente, um conjunto de expectações estáveis e abrangentes quanto ao que os outros membros do grupo estão fazendo e de que maneira reaqirão ao que êle diz e faz.

\section{Explicação do Comportamento Humano nas Organizações}

Os teóricos da administração adotaram, em suas construçőes, diferentes séries de pressupostos ao definirem e explicarem o comportamento dos membros das organizações.

Segundo o Taylorismo, os empregados das organizações eram essencialmente instrumentos passivos, capazes de executar o trabalho e receber ordens, mas sem poder de iniciativa e sem exercerem influência provida de qualquer significação.

Consoante os teóricos do comportamentalismo humanista, os membros das organizações são portadores de atitudes, valôres e objetivos, mas precisam ser motivados ou induzidos para participarem do sistema comportamental da organização. Haveria uma defasagem entre seus objetivos pessoais e os da organização, responsável por conflitos que fariam com que os fenômenos do poder, as atitudes e o moral adquirissem importância capital para e explicação do comportamento da organização.

Para Herbert Simon e J. March $\left(^{\star * * *}\right)$. os membros da organizacão são, sobretudo, tomadores de decisões e resolvedores de problemas, constituindo os processos de percepção e raciocinio elementos básicos na explicação do seu comportamento organizacional.

(*) March, J. G., e Simon, H. A. - "Teoria das Organizações" Rio de Janeiro, Fundação Getúl:o Vargas, 1967, pág. 6.

$\left({ }^{* *}\right)$ Obra citada, pág. 6.

$(* * *)$ Simon, H. A. - "Comportamento Administrativo" - Rio de Janeiro, Fundação Getúlio Vargas, 1965, Série Administração para o Desenvolvimento, $\mathrm{n}^{\circ} 9$, pág. XVII.

$\left({ }^{\star \star \star *}\right)$ Obra citada, pág 10 . 
Ponderam, no entanto, êsses autores, que nada há de contraditório entre as referidas séries de pressupostos, que, assim, não se excluem, antes se completam. Os próprios teóricos que as adotaram se distinguem pela maior ou menor ênfase que atribuiram a uma delas. Disso resulta que, nas obras do movimento de administração cientifica, tenha preeminência o modêlo do empregado como instrumento. Nos escritos dos adeptos da escola das relações humanas ressalta a prevalência do modêlo que salienta atitudes e motivações e que tem ensejado pesquisas sôbre burocracia, relações humanas, liderança e supervisão. O terceiro modêlo, que enfatiza os aspectos racionais e intelectua:s do comportamento na organização, tem-se refletido em trabalhos de economistas e outros autores sôbre o processo de planejamento e de psicólogos sôbre comunicações e solução de problemas na organização (processo decisório).

\section{O Equilibrio da Organização}

O objetivo da organização é, indiretamente, um objetivo pessoal de todos os seus participantes (empresários, empregados e clientes, tomadas essas expressões em sentido lato, para abranger todos os tipos de organização). Êsse objetivo comum constitui o meio pelo qual suas atividades organizativas se fundem, com a satisfação de seus diversos motivos pessoais.

- Como acentua Simon, os objetivos do empresário acham-se estreitamente relacionados com a sobrevivência da organização e os objetivos do cliente ligam-se diretamente aos objetivos da organização. Já os objetivos do empregado não se ligam -a qualquer daqueles dois, embora se incorporem ao esquema da organização em virtude da existência de sua área de aceitação, construída e ampliada através dos processos de influenciação. De qualquer modo, o caráter especial do comportamento organizacional é devido à existência dêsses três papéis-tipicos.

\section{Sintese do Modêlo Decisório de Herbert Simon}

Deter-nos-emos, nesta introdução, em ligeira sintese do modêlo decisório de S'mon, a cuja obra, já referida, voltaremos a recorrer mais demoradamente no desenvolvimento dêste trabalho, que se ocupará especificamente do processo decisório e de suas repercussões sôbre as organizações.

Anteriormente a Simon, os teóricos da organização davam ênfase à execução, ao como fazer.

Simon, partindo da idéia fundamental de que administrar é antes de tudo decidir, preocupou-se, sobretudo, com o que fazer, e, conseqüentemente, com o problema relativo ao processo de es- 
colha que conduz à ação, a fim de que se passe a decidir melhor, e não apenas de acôrdo com a preocupação predominante de seus predecessores, executar melhor, através de processos de racionalização do trabalho.

Deve, assim, a Administração cuidar simultâneamente da decisão e da execução, não podendo admitir a pretensa dicotomia entre a Política (que seria responsável pelas diretrizes e fixação de objetivos) e a Administração (à qual se reservaria exclusivamente a execução).

$\mathrm{Na}$ realidade, o ponto-de-vista atualmente dominante sôbre esta antiga controvérsia é no sentido de reconhecer, com o apoio, inclusive, de modernos cientistas políticos. que Politica e Administração não são estanques, antes constituem um continutum, que apresenta aspectos comuns a ambas.

Outros aspectos da concepção do processo decisório que merecem, desde logo, destaque, em abordagem inicial do assunto, ao qual daremos oportunamente maior desenvolvimento, são os seguintes:

1. O processo decisório comporta três fases, estreitamente relacionadas com os estágios da solução de problemas:

a) Qual é o problema? Nesta primeira fase, efetua-se a coleta de informações, mediante a análise do ambiente, com vistas à identificação das situações que, exigem decisão;

b) Quais sãos as alternativas? Nesta segunda fase, desenvolve-se a atividade de estruturação, mediante a criação, o desenvolvimento e a análise de possiveis curso de ação;

c) Qual é a melhor alternativa? Nesta terceira fase, de avaliacão, escolha ou decisão, procede-se à seleção de uma linha determinada de ação entre as disponiveis. $\left({ }^{*}\right)$

2. A decisão é, assim, apenas um ponto, o último estágio do processo decisório, para o qual estão condicionados os membros da organização.

3. A execução da decisão reabre, no nível h'erárquico inferior, o ciclo do processo decisório, já que exigirá estruturação e escolha de uma linha de ação para executá-la, e assim dinâmica e sucessivamente.

4. A racionalidade do processo decisório é afetada por obstáculos factuais e valorativos, inerentes aos limites da racionali-

(*) Simon, H. A. - "A Capacidade de Decisão e de Liderança" Rio de Janeiro e São Paulo, Fundo de Cultura, 1963, págs. 14/17. 
dade. Êsses obstáculos são representados por uma série de disfunções do processo de comunicação ou por elementos valorativos. procurar:

5. Para aumentar a racionalidade das decisões, deve-se

a) Dispor de tôdas as informações a tempo;

b) Examinar tôdas as alternativas e respectivas consequiências;

c) Tomar a decisão, tanto quanto possivel, no ponto de execução;

d) Integrar, no processo decisório, o sistema de valôres da organização a fim de imprimir às decisões a desejável uniformidade valorativa através de sua coordenação pelas idéias (nesse sentido, o modêlo de Simon é racionalista e se aproxima do modêlo de Taylor).

6. As decisões estão sujeitas a contingências de acomodação. A alírnativa finalmente escolhida não permitirá a realização completa e exata dos objetivos visados. Corresponderá, com as limitações que line são imanentes, à melhor solução encontrada em cada conjuntura. $\mathrm{O}$ ambiente restringe inevitàvelmente a quantidade e a qualidade das alternativas, concorrendo para o estabelecimento de um nivel máximo, mas não ideal, de consecução de um objetivo.

Uma sintese, em têrmos preliminares, do pensamento de Simon pode ser proporcionada através de sua definição de organização:

"Uma organização é, afinal de contas, um conjunto de pessoas, e o que ela faz é realizado por essas pessoas. As atividades de um grupo de pessoas tornam-se organizadas ùnicamente na medida em que essas permitem quie suas decisões e seu comportamento sejam influenciados pela participação na orqanização." (Comportamento Administrativo - pág. 129).

\section{CAPÍTULO II}

\section{EXPOSIÇAOO DO PENSAMENTO DE SIMON}

\section{1. "Principios de Administração"}

Herbert Simon recusa validade científica aos clássicos "princípios de administração", que prefere denominar provérbios de administração, procurando demonstrar seu caráter ambíguo e mùtuamente contraditório, e admitindo, quando muito, a aplicabilidade alternativa de cada um dêles a determinadas conjunturas organizacionais.

(*) "Comportamento Administrativo", obra já citada, pág. 129. 
Julga inoportuna, ainda, a formulação de principios científicos de administração, cujo surgimento efetivo dependerá da prévia criação, pelos cientistas da administração, de um vocabulário que lhes permita descrever, em têrmos exatos, a morfologia e o funcionamento das organizações.

Abstém-se, assim, sob o ponto-de-vista teórico, de formular qualquer princípio de administração, limitando-se a considerar que a tomada de decisões é o cerne da administração e que o vocabulário da teoria administrativa deve emanar da lógica e da psicologia pertinentes ao processo de escolha dos sêres humanos. Antecipa, não obstante, que uma teoria geral de administração deve incluir principios de organização, que assegurem quer decisões corretas, quer ação efetiva, afirmando, ainda, que "só se podem. compreender as condições básicas de aplicabilidade dos principios administrativos por meio de uma análise do processo administrativo em têrmos de decisões. $\left({ }^{\star}\right)$

\section{Limites da Racionalidade}

Procurando sintetizar o conteúdo dos capitulos 4 (O Papel da Racionalidade no Comportamento Administrativo) e 5 (A Psicolog; a das Decisôes Administrativas) de sua obra "Comportamento Administrativo", Simon afirma que "a principal preocupação da teoria administrativa reside nos limites racionais e irracionais do comportamento social dos sêres humanos. A teoria administrativa é, na sua essência, a teoria da racionalidade intencional e limitada do comportamento dos sêres humanos, que contemporizam porque não possuem meios para maximizar."

Por limites de racionalidade entende os fatôres que determinam com que capacidade, valôres e conhecimento o membro da organização realiza seu trabalho. O individuo é limitado, ainda, pela extensão dos conhecimentos das coisas relacionadas com o trabalho. Isto se aplica tanto ao conhecimento básico, requerido para a tomada das decisões (por exemplo, o projetista de pontes deve conhecer os fundamentos de mecânica), quanto às informações requeridas para tornar suas decisões apropriadas àquela situação.

As deficiências resultantes dos limites da racionalidade imprimem muitos elementos de incongruência ao comportamento real, não permitindo que êste coincida com o comportamento ideal, e sim, que dêle mais ou menos se aproxime.

( *) "Comportamento Administrativo", obra citada, pág. 280. 


\section{Premissas Factuais e Premissas de Valor}

Trata-se fundamentalmente de distinção filosófica, para cujo estabelecimento Simon se reporta à moderna escola do positivismo lógico.

Proposições factuais são afirmações acêrca do mundo que se pode ver e da maneira como funciona. Em principio, podem ser testadas, a fim de determinar-se se são verdadeiras ou falsas.

As proposições valorativas, ao contrário, pelo seu caráter abstrato e subjetivo, não comportam julgamento, em têrmos objetivos, sob o critério de certo ou errado.

As decisões possuem, ao mesmo tempo, conteúdo ético e conteúdo factual. Afirmar que existe um elemento ético envolvido em tôda a decisão não implica, porém, em afirmar que as decisões englobam apenas elementos éticos. Ulma decisão representa uma conclusão tirada de um conjunto de premissas de fato e de valor.

Por outras palavras, os problemas administrativos englobam questões factuais, envolvidas em elementos éticos.

As primeiras são operacionais e suscetiveis diretamente de julgamento quanto à sua correção. Os segundos, vinculando-se a objetivos não diretamente suscetiveis de operacionalização, dada sua expressão abstrata e valorativa, não podem ser avaliados, a não ser indiretamente, isto é, incidindo a avaliação sôbre a correção dos meios empreqados, através de uma cadeira de meios e fins intermediários resultante da decomposição de objetivos (fins) em subobjetivos (meios).

Em suma, os subobjetivos substituem os objetivos mais amplos, como parte de um processo em que, para fins de decisão e ação, substitui-se a complexa realidade por um modêlo simplificado dessa mesma realidade.

Nessa cadeia ou hierarquia de meios e fins chega-se, finalmente, a um ponto em que as conexões entre meios e fins se tornam tão tênues e imprecisas que a análise deixa de oferecer interêsse à Administração, isto porque os objetivos finais, dominados por elementos éticos, pertencem, preferencialmente, às cogitações da Politica.

\section{Comportamento Administrativo}

Simon assim enuncia o tema central de seu estudo:

"O comportamento administrat'vo consiste de uma complexa rêde de processos decisórios que se destinam a influenciar o comportamento do pessoal de execução, ou seja, daqueles que realizam de fato o trabalho "físico" da organização. Por anatomia da organização enten- 
de-se a distribuição e localização das funções decisórias. Sua fisiologia consiste nos processos pelos quais a organização influencia as decisões de cada um de seus membros, tornecendo-lhes as premissas para essas decisões."

A decisão emerge, assim, de uma sucessão de atos preparatórios. Só aparentemente a decisão é um ato atribuivel apenas a quem a toma formalmente e assume, na hierarquia administrativa, a responsabilidade por seu acêrto e consequiências. Realmente, os canais de comunicação, tormais e informais, que transitam pelo responsável nominal pela escolha da alternativa convertida em decisão, são portadores de inúmeras informações transmitidas por membros da organização localizados em diversas posições, nas quais essas informações, resultantes da sintese de fatos e ocorrências pelos mesmos conhecidas, sofrem modificações e reformulações sucessivas, que as transformam em premissas, algumas das quais se incorporam, finalmente, à escolha ou decisão definitiva.

\section{Tomada de Decisões no Processo Administrativo}

Os processos administrativos são o conjunto de técnicas que facilitam o desenvolvimento dos esforços grupais para o desempenho de uma tarefa comum.

Em última análise, os processos administrativos são processos decisórios, assim como a própria Administração pode ser concebida como um processo continuo e dinâmico de tomada de decisões. Em verdade, os processos administrativos consistem substancialmente: a) no isolamento dos membros da organização de certos elementos (ou premissas) das decisões, mediante o estabelecimento de métodos de rotina para selecionar e determinar êsses elementos; b) na sua comunicação aos membros da organização que dêles devam necessàriamente ter conhecimento para orientação das próprias decisões no contexto do processo decisório programado pela organização.

Assim sendo, a organização substitui a faculdade de decisão livre e individual de cada um de seis membros por um processo decisório por ela adredemente elaborado.

Nesse processo decisório, figuram habitualmente os seguintes elementos, além de outros: a) a especificação das funções dos membros da organizacão. fixando o âmbito e a natureza de seus deveres; b) a distribuição da autoridade, isto é, a determinação de arem terá poder nara tomar novas decirões que afetem cada membro da organização; c) o estabelecimento de tantos limites à faculdade de agir do membro da organização quantos sejam necessários para coordenar as atividades dos demais membros da organização . 


\section{A Tomada de Decisões e sua Exiecução}

A participação do pessoal não executivo na consecução dos objetivos da organização se efetua na medida em que influi nas decisões do pessoal de linha (ou operativo), situado na base da hierarquia administrativa.

Nas pequenas organizações essa influência se exerce diretamente na supervisão sôbre o pessoal executivo. Já nas grandes organizações, existem diversas camadas intermediárias, constituídas por diferentes niveis de supervisores, que recebem as influências da cúpula organizacional e as transmitem ao pessoal de linha.

O têrmo influência é empregado deliberadamente em lugar de direção, porque é mais abrangente que esta e melhor satisfaz aos designios teóricos do autor. $\mathrm{Na}$ realidade, a direção é uma das diversas maneiras pelas quais se exerce a influência organizacional, como veremos oportunamente.

\section{A Decisão sob o ponto-de-vista do Individuo por ela Responsável}

\section{a) A gradação da influência}

Os processos de influência (ou a fisiologia do processo decisório) se exercem, em geral, parcialmente sôbre o que fazer e deixar em maior liberdade o agente da ação sob o aspecto do como fazer.

Mesmo o que fazer comporta gradação, em limites mais amplos ou restritos.

Qualquer que seja essa gradação, o comportamento do agente executivo da organização é suscetivel de contrôle se as premissạ de valor e de fato em que se baseiam suas decisões forem adredemente especificadas. Para um contrôle total, a autoridade fará para seu subordinado especificação total. Para um contrôle parcial, a especificação será parcial.

Dada a natureza especial das premissas de valor, não suscetiveis de avaliação empirica, em têrmos de certo ou errado, sòmente as premissas factuais devem ser deixadas, em parte, a critério do subordinado, se se deseja avaliar posteriormente a correção de suas decisões. A se deixar também a seu arbítrio premissas de valor, isso implicará na impossibilidade da aplicação à sua decisão do critério de correção ou incorreção, o qual não se aplicará às premissas valorativas que por êle foram subjetivamente selecionadas.

Praqmàticamente, o sistema de autoridade funciona na hase da determinação, da cúpula para os niveis hierárquicos imediatamente inferiores, de metas ou missões de caráter geral, que são 
sucessivamente desdobradas em sua execução através dos vários níveis hierárquicos, de tal maneira que o último nivel desempenhe realmente a parte da tarefa geral correspondente áos aspectos sôbre os quais está habilitado plenamente a tomar decisões de sua responsabilidade. É nesse sentido que o Regulamento de Campanha do Exército Norte-americano determina que "nenhuma ordem deve invadir a esfera de um subordinado; deve abranger tudo que escape à autoridade independente do subordinado, mas nada além disto". ( $\left.{ }^{*}\right)$

É impossivel descrever exaustivamente tôda a gradação da influência no processo decisório. Na síntese de Simon, "para compreender o processo decisório numa organização é necessário ir muito além do simples estudo das ordens imediatas que são dadas pelo superior ao subordinado. É necessário investigar como os subordinados são influenciados por ordens permanentes, pelo treinamento e pela revisão de seus atos pela organização. É preciso estudar os canais de comun'cação na organização, a fim de determinar qual a importância das informações que recebe para suas decisões. Quanto maior a esfera de arbitrio permitida ao subordinado, mais importantes se tornam êsses tipos de influência que não dependem do exercício da autoridade formal."

\section{b) Modos e Formas de Influência Organizativa}

Para obter a aceitação e o cumprimento das diretrizes e decisões oriundas dos altos escalóes da hierarquia administrativa, cumpre à organização adotar convenientes processos de influenciação do comportamento do seu pessoal.

Simon classifica essas influências em duas categorias, ressalvando, porém, que não são mùtuamente exclusivas: a) a imposição das diretrizes e decisões da cúpula organizacional, mediante a utilização da influência das autoridades e serviços consultivos e informativos; $b$ ) a formação, no próprio empregado, de at'tudes, de hábitos e de um estado de espírito que o levem a tomar as decisões consideradas vantajosas para a orqanização. Êste último tipo de influência se exerce pelo desenvolvimento no empregado de lealdade orqanizativa (identificações com a organização), de uma preocupação com efic'ência, de aconselhamento e prestação de informações, e ainda, através de treinamento.

A autoridade, o aconselhamento, a informação e o treinamento são influências "externas." O critério de eficiência e as identificações com a organização constituem as influências "internas."

A institucionalização do processo decisório na orqanização reclama que uma das características da autoridade seja a especialização na tarefa de tomar decisões, de modo a permitir que

(*) "Comportamento Administrativo", obra citada, pág. 262. 
cada uma delas ocorra no ponto da organização em que pode ser tomada de maneira mais eficiente.

O uso apenas da autoridade para o contrôle das decisões é reconhecidamente insuficiente.

É necessário que, através da manipulação de outros tipos de influenciação, os subordinados se tornem capazes de tomar as próprias decisões ou colaborar adequadamente na formulação de premissas úteis à escolha pelos supervisores.

Os membros da organização devem, pois, ser envolvidos por um ambiente psicológico que condicione suas decisões aos objetivos da organização e lhes proporcione as informações necessárias para que as tomem corretamente.

\section{ช. Classificicação de Cargos e Seleção}

Assim sendo, e como pondera Simon, "os problemas da organização não podem ser tratados sem considerar as especificações dos requisitos dos empregados que vão preencher os cargos criados pela organização. Todo o campo da classificação de cargos precisa, nesse particular, ligar-se mais estreitamente com a teoria da organização. A estrutura "ótima" da organização constitui uma variável cuja configuração depende do pessoal por ela admitido. Reciprocamente, a classificação de um cargo é uma variável que depende do grau de centralização ou descentralização que se deseja, ou que se prevê. para o funcionamento da forma organizativa escolhida." $\left({ }^{\star}\right)$

\section{Especialização}

Dadas as diferenças individuais, a variabilidade das aptidões e a diversidade das capacidades profissionais, as organizações se caracterizam pela especialização, vale dizer, pela delegação de certos encargos a determinados de seus membros ou setores de trabalho.

Habitualmente, dá-se ênfase à especialização horizontal - à divisão do trabalho como decorrência da preocupação com sua execução pròpriamente dita, com o como fazer.

Ao estudo do processo decisório interessa, porém, sobretudo, a especializaçăo vertical, isto é, a divisão vert cal do trabalho, suscetivel de representação por uma pirâmide ou hierarquia de autoridades que igualmente reflita a especialização das funções decisórias entre os membros dessa hierarquia.

Sequndo Herbert Simon $\left({ }^{\star \star}\right)$ há pelo menos três motivos que justificam a especialização vertical nas organizações: a) a

$\left({ }^{*}\right)$ "Comportamento Admin'strativo", obra citada, pág. 266.

$\left({ }^{* \star}\right)$ "Comportamento Administrativo", obra citada, pág. 266. 
existência de especialização horizontal torna a especialização vertical absolutamente necessária à obtenção da coordenação entre o pessoal operativo; b) do mesmo modo que a especialização horizontal enseja que êsse pessoal desenvolva ma:or habilidade e destreza no desempenho de suas tarefas. a especialização vertical permite, por seu turno, maior exatidão na tomada de decisões; c) a especialização vertical permite que se responsabilize o pessoal de linha por suas decisões (para cuja apreciação o pessoal de supervisão está convenientemente habil tado como decorrênria da institucionalização do processo decisório).

\section{Coordenação}

O comportamento conducente aos objetivos organizacionais reclama não só decisões corretas, como também sua plena aceitação.

A centralização da função decisória, capaz de estabelecer um plano geral e coordenado, é alcançável mediante o exercicio da autoridade, de maneira que um plano geral de operações guie as atividades de todos os membros da organização, concorrendo para que adotem decisões coerentes, que se combinem convenientemente para que os objetivos estabelecidos sejam alcançados.

Essa coordenação, de caráter processual, faz surgir, assim, as linhas de autoridade e define a esfera de atividade de cada empregado, equivalendo ao estabelecimento da organização pròpriamente dita, ou à descrição generalizada dos comportamentos e das relações entre os seus membros. Dela, Simon distingue a coordenação substantiva, que especifica o conteúdo do trabalho de cada membro da organização, de acôrdo com sua especialidade.

O propósito principal do planejamento e da organização que antecede qualquer atividade administrativa não é apenas colocar cada participante no cargo em que possa atuar melhor, mas permitir que cada um tenha certeza em relação ao que os outros irão fazer. Talvez ficasse mais clara a discussão da teoria administrativa, lembra Simon, se usássemos o têrmo cooperação para designar tôdas as atividades em que os participantes compartilham de um obietivo comum e o têrmo coordenação para nos referir ao processo de informar cada um dêles a respeito do comportamento dos outros. Conseqüentemente, a conneração poderá tornar-se ineficaz se não houver coordenação. (*)

\section{Comunicações}

A comunicação se faz através de canais definidos, seja em virtude de um plano formal ou de programas informais, que

(*) "Comportamento Administrativo", obra já citada, pag. 85 . 
gradualmente se desenvolvem. As informações e estimulos trans portam-se de suas tontes aos pontos de decisão; as instruçoes movem-se dos pontos de decisão aos pontos de ação; as informa'ções sôbre os resultados transmitem-se dos pontos de ação aos pontos de decisão e contrôle. $\left({ }^{*}\right)$

Quanto maior fôr a eficiência das comunicações maior será sua utilidade como instrumento de coordenaçáo.

\section{Descentralização ou Centralização das Decisões?}

A análise do processo decisório evidencia a possibilidade da melhor distribuição das responsabilidades da decisão por tôda a organização e, conseqüentemente, enseja a apreciação das vantagens e desvantagens relativas a essa descentralização.

O primeiro fator condicionante da descentralização é a capacidade dos membros da organização para a tomada de decisões.

Outro requisito importante será proporcionar-lhes melhores recursos, através de convenientes processos de influenciação, para que tomem corretamente as decisões que a organização precisa delegar-lhes. Nesse sentido, convém acentuar que a retificação dos processos decisórios porventura responsáveis por decisoes incorretas de subordinados sobreleva, em têrmos de rendimento para a organização, a simples correção de decisões erradas.

Cumpre, também, considerar a questão a longo prazo, ev1tando que considerações imediatistas deformem sua perspectiva $e$ conduzam a organização à conhecida contingência de ver as árvo. res sem ver a floresta. Se bem que, a curto prazo, possam ocorres razões favoráveis à centralização da decisão (maior competência e segurança da autoridade central que decide), essa centralização, a longo prazo, significará possivelmente excessiva carga de trabalho para a autoridade central, em prejuizo da tomada de decisões mais importantes, e o aproveitamento apenas parcial da capacidade de trabalho de subordinados.

Acresce que se a centralização das decisões pode concorrer, em determinadas condições presentes, para maior eficácia da organização, pelo fato de aquelas decisões serem mais adequadas aos objetivos organizacionais, tal vantagem poderá tornar-se corltraproducente em relação aos benefícios que da descentralização do processo decisório adviriam futuramente para a eficiência da organização.

Também não se deve desprezar a circunstância de que a centralização das decisões exige maior dispêndio de tempo e di-

(*) March e Simon, obra já citada, págs. 207 e 210. 
nheiro para sua comunicação aos niveis hierárquicos inferiores. No verdade, ocorre na centralização uma duplicação do processu decisório, pelo maior uso dos canais de comunicação, cujo custo pode deixar de compensar a eventual vantagem em exatidão da decisão centralizada, exatidão que, através de processos adequa dos de influenciação, também poderia vir a ser alcançada em regime de descentralização.

Acrescente-se que o desconhecimento, em tôdas as suas minúcias, pelos níveis superiores da hierarquia administrativa, de fatos que sejam conhecidos prioritária e completamente pelos niveis inferiores, pode aconselhar a descentralização do processo decisório, a bem até mesmo de sua maior exatidão.

Como vemos, excetuadas as macro-decisões, que devem necessàriamente caber à cúpula da organização, por todos os titulos (predominância de premissas valorativas intimamente relacionadas com as diretrizes e os objetivos básicos da organização, facilidade de obtenção pelos niveis hierárquicos superiores de melhores e mais rápidas informações etc.). há, em geral, preponderância de razões em favor da descentralização das decisões administrativas.

Uma orientação definitiva, em cada caso concreto, deve, no entanto. sopesar convenientemente tôdas as condicões que mais aconselhem a centralizacão ou a descentralização. Neste sentido, são as advertências de Herbert Simon:

"Podemos concluir que certa dose de centralização é indispensável para conseguir as vantagens da organização, isto é, a coordenação, a especialização e a responsabilidade. Por outro lado, os custos da centralizar ção não devem ser esquecidos, porque pode atribuir-se a pessoas altamente remuneradas decisões que não merecem sua atenção. Pode levar à duplicação de funções que tornam os subordinados inúteis. É preciso dispor, muitas vêzes, de meios de comunicação muito caros. A informação indispensável à decisão correta pode encontrar-se ùnicamente ao alcance do subordinado. Finalmente a centralização torna ociosa e desperdiça a poderosa capacidade coordenadora do sistema nervoso humano (em casos de excessiva e desaconselhável especializacão), substituindo-o por um mecanismo coordenador interpessoal. Estas são as consideracões que devem estar presentes auando se tiver que determinar o grau em que as decisões deverão ser centralizadas ou descentralizadas." ( $\left.{ }^{*}\right)$

(*) "Comportamento Administrativo", obra jă citada, pág. 279. 
"A questão não é saber se se deve descentralizar, mas até que ponto deve ser feita a descentralização. O que se procura é uma posição correta: deseja-se descobrir um nivel adequado na hierarquia da organização - nem tão elevado, nem tão baixo - de cada importante classe de decisão." (A Capacidade de Direção e Licença", obra já citada, pág. 67).

\section{CAPÍTULO III}

\section{AJUSTAMENTOS DAS ORGANIZAÇÕES AO PROCESSO DECISÓRIO}

\section{Planejamento}

A teoria administrativa deve estudar os problemas do planejamento e a administração das organizações com vistas a que estas realizem eficientemente suas funções e alcancem eficazmente seus objetivos.

Presentemente, as preocupações pragmáticas em tôrno das organizações convergem, sobretudo, para os problemas da distribuição de funções e da estrutura formal da autoridade, relegando a segundo plano os aspectos da influenciação organizacional e do sistema de comunicações, tão importantes na dinâmica do processo decisório.

$\mathrm{O}$ atual estágio em que se encontram os conhecimentos sôbre o processo decisório, quer quanto à sua anatomia, quer quanto à sua fisiologia, enseja, no entanto, que as atenções da Teoria da Organização se voltem enfàticamente para o estudo da distribuição real das funções decisórias.

Simon, estudando os tipos de comportamento que resultam da dinâmica do processo decisório, distingue:

a) o planejamento substantivo, que corresponde à atividade pela qual a organização toma decisões amplas, relativas aos valôres que orientarão suas atividades, métodos gerais que vai usar para alcançar êsses valôres, e aos conhecimentos, habilidades e informaçöes de que necessitará para determinadas decisões dentro dos limites da política estabelecida e para levar a efeito estas decisōes;

b) planejamento processual, que corresponde à preparação do meio ambiente psicológico da decisão e que consiste em projetar e estabelecer os mecanismos que dirigirão a atenção e canalizarão as informações e os conhecimentos, de modo a permitir 
que as decisões especificas diárias se conformem ao plano substantivo;

c) a execução do plano, através de decisões e atividades diárias que se enquadram no arcabouço propiciado pelas etapas anteriores. $\left({ }^{*}\right)$

Assinala, ainda, Simon que, em consequência, surgem dois importantes problemas para a teoria administrativa:

a) em relação ao planejamento substantivo: de que maneira essa rêde de decisões deve ser construida, qual a divisão de trabalho adequada entre as amplas decisões "planejadoras" (macrodecisões) e as decisões "executoras" mais restritas (micro-decisões);

b) em relação ao planejamento processual: criação de mecanismos que tornem efetivo o contrôle das decisões executivas a partir das decisões planejadoras. $\left({ }^{\star *}\right)$

Por outro lado, Simon enumera os seguintes mecanismos de influenciação de que podem valer-se as organizações para sistematizar as decisões de seus membros:

a) a organização divide o trabalho entre seus membros, e ao atribuir a cada um o cumprimento de determinada função, dirige e limita sua atenção exclusivamente àquela tarefa.

b) a organização estabelece padrões de desempenho para cada função;

c) a organização comunica as decisões de cima para baixo (assim como lateralmente e para o alto), através de seus vários escalões, estabelecendo um sistema de autoridade e influenciação. A forma mais familiar dêsse processo é a hierarquia da autoridade formal, embora seja de igual importância a atribuição a determinados indivíduos da função formal de assessoramento, assim como o desenvolvimento, em qualquer organização real, de um sistema informal de influenciação, baseado, em parte, no status formal, em parte nas relações sociais.

d) a organização proporciona canais de comunicação que ise estendem em tôdas as direções e através dos quais fluem as informações para a tomada de decisões. Esses canais podem ser formais ou informais. Os primeiros se baseiam, em parte, sôbre as linhas da autoridade formal e em parte diferem delas, enquanto que os segundos se acham estreitamente relacionados com a organização social informal.

(*) "Comportamento Administrativo", obra citada, pág. 7 .

(**) Idem, pág. 115. 
e) a organização treina e endoutrina seus membros (processo de "internalização" das influências). (

\section{Organização Formal e Organização Informal}

É inevitável, como se depreende do item anterior, a existência, paralelamente à organização formal, tal com esta é planejada ideal e adredemente, da organização informal, que, permeada na realidade das coisas, compreende relações interpessoais que ocorrem dentro da organização e que afetam freqüentemente suas decisões.

A organização informal habitualmente complementa a organização formal e pode concorrer, salvo em aspectos disfuncionais, para a eficácia da organização. Ambas participam, na realidade, da dinâmica da organização, na qual a organização formal representa uma carta de intenções, sôbre cuja efetiva execução dirão os resultados da organização dinâmica.

Motivos não há, assim, nem mesmo de caráter teórico, que justifiquem qualquer orientação sistemática no sentido da extinção da organização informal, ressalvada, òbviamente, a supressão daqueles aspectos que se revelem disfuncionais.

Quanto aos aspectos funcionais da organização informal, cumpre, mesmo, ao moderno administrador, maximizar suas vantagens, assim como minimizar as desvantagens ou disfuncionalidades da organização formal.

Estudando o problema das relações entre ambas, Simon destaca as seguintes funções da primeira em relação à segunda:

"Constitui uma função particularmente da organização formal evitar o desenvolvimento de problemas políticos na organização - a luta pela influência e autoridade - a ponto de se tornarem prejudiciais ao funcionamento dela. Cabe-lhe, ademais, a função de identificar e eliminar duplicações e superposições desnecessárias no trabalho das várias partes da organização. Talvez a função mais positiva da èstrutura formal, relativamente à estrutura informal, seja estimular o desenvolvimento $d_{a}$ última de forma construtiva. Em outras palavras, a distribuição apropriada de deveres e a manutenção de canais de comunicação adequados podem

(*) "Comportamento Administrativo", obra citada; págs. 121/122. 
eliminar a necessidade de estabelecer-se canais informais e estimular, na estrutura informal, o intercâmbio de idéias e o desenvolvimento de atitudes construtivas." $\left({ }^{\star}\right)$

CAPÍTULO IV

\section{NOVAS PERSPECTIVAS PARA AS ORGANIZAÇŐES}

Seção I - Processos Decisórios Programados e Não-Programados e suas Conseqüências mais Imediatas

Já vimos que a terceira fase do processo decisório consiste na escolha da melhor linha de ação, dentre as alternativas satisfatórias (uma vez que os limites da racionalidade impedem que a escolha recaia em alternativa ótima ou ideal).

Ao conjunto de reações que integram essa linha de ação denomina-se programa de ação, ou simplesmente programa. Essa palavra é usada no trabalho com os computadores em sentido análogo, se bem que mais preciso: prescrição ou estratégia detalhada que rege a seqüência de reações de um sistema a um conjunto de tarefas complexas. $\left({ }^{\star \star}\right)$

O comportamento humano, sobretudo nas organizações, é, em grande parte, regido por programas de ação ou repertórios de ação adequados a diferentes situações.

O processo decisório é programado, rotinizado ou estruturado na medida em que a escolha (ou decisão) e conseqüentes atividades de execução se tornam simplificadas pelo fato de certos estimulos definidos provocarem reações fixas, repetitivas e rotineiras.

O processo decisório é não-programado, não-rotinizado ou não-estruturado na medida em que as decisóes e conseqüentes atividades de exectução tenham que ser precedidas pela formação de programas e solução de problemas importantes e complexos.

A distinção entre decisões programadas e não-programadas não é estanque. Realmente, não constituem tipos distintos substancialmente, mas um continutum, com decisões altamente programadas em uma extremidade e decisões altamente não-programadas na outra. $\left({ }^{\star * *}\right)$

O valor da distinção consiste em que diferentes técnicas são utilizadas para tratar os aspectos rotineiros ou não-rotineiros da tomada de decisão, como ilustra o quadro seguinte. $\left({ }^{\star \star \star \star}\right)$

(*) «Comportamento Administrativo», obra já citảda, pág. 174.

${ }^{* \star}$ ) «A Capacidade de Decisão e de Liderança», obra já citada, pág. 20 .

$\left({ }^{\star \star *}\right)$ Idem, pág. 22.

$(* \star \star \star)$ Idem, pág. 22 . 


\begin{tabular}{|c|c|c|}
\hline \multirow{2}{*}{ TIPOS DE DECISÃo } & \multicolumn{2}{|c|}{ TÉCNICAS DE TOMAR DECISÃO } \\
\hline & TRADICIONAIS & MODERNAS \\
\hline $\begin{array}{l}\text { Programadas: } \\
\text { Decisões repetitivas e de rotina } \\
\text { A organização desenvolve pro- } \\
\text { cessos especificos para tratá. } \\
\text { las }\end{array}$ & $\begin{array}{l}\text { 1. Hábito } \\
\text { 2. Rotina administrativa: } \\
\text { Procedimentos padronizados } \\
\text { de operação }\end{array}$ & $\begin{array}{l}\text { 1. Pesquisas operacionais: } \\
\text { Análise matemática } \\
\text { Modelos } \\
\text { Simulação com computador } \\
\text { 2. Processamento eletrônico de } \\
\text { dados }\end{array}$ \\
\hline $\begin{array}{l}\text { Não Programadas: } \\
\text { Decis̃os politicas mal estrutu- } \\
\text { radas. } \\
\text { Tratadas por processos gerais de } \\
\text { resolver problemas }\end{array}$ & $\begin{array}{l}\text { 1. Julgamento, intuição e cria- } \\
\text { tividade } \\
\text { 2. Normas práticas } \\
\text { 3. Seleção e treinamento de } \\
\text { executivos }\end{array}$ & $\begin{array}{l}\text { Técnicas heurísticas de resolver } \\
\text { problemas aplicadas a: } \\
\text { a : Treinamento de indivíduos } \\
\text { que tomam decisōes } \\
\text { b) Montagem de programas } \\
\text { heuristicos de computado- } \\
\text { res. }\end{array}$ \\
\hline
\end{tabular}

- Simon resume do seguinte modo as conseqüências da modernização das técnicas da tomada de decisões programadas, muitas das quais já vão sendo automatizadas:

a) o computador eletrônico está trazendo, com rapidez inesperada, um elevado nivel de automação na rotina, na tomada de decisões programadas e no processamento de dados que, outrora, cabiam aos empregados.

b) a área da tomada de decisões programadas expande-se ràpidamente à medida que descobrimos meios de aplicar os instrumentos da pesquisa de operações a tipos de decisões que, até hoje, têm sido consideradas como intelectuais especificamente, mas não exclusivamente. às decisões de nivel intermediário na administração, na área de produção e almoxarifado.

c) o computador estendeu a potencialidade das técnicas matemáticas a problemas demasiadamente vastos para serem tratados por instrumentos menos automáticos e ampliou muito a gama de decisões programáveis, pela contribuição da nova técnica de simulação.

d) as emprêsas estão agora começando a descobrir maneiras de reunir os dois primeiros dêsses aperfeiçoamentos: combinar as técnicas matemáticas de tomar decisões sôbre variáveis cumulativas de niveis intermediários com as técnicas de processamento 
de dados para pôr em execução detalhada essas decisões nos niveis administrativos. $\left({ }^{*}\right)$

A gradativa expansão, graças às modernas técnicas, da área das decisões programadas, com a conseqüente redução da área das decisões não-programadas, quer nos niveis médios, quer nos niveis superiores da administração, encontra, porém, seus limites, por envolver, sob certos aspectos, problemas inacessiveis ao tratamento matemático.

Acresce que a utilização dessas novas técnicas é muitas vêzes factivel sob o ponto-de-vista estritamente tecnológico, mas não sob o ponto-de-vista econômico.

O desenvolvimento tecnológico de modernas feições técnicas do processo decisório não-programado dependerá do resultado de complexas e delicadas pesquisas psicológicas a respeito da natureza da solução dos problemas humanos, cuja compreensão carece de maior aprofundamento (embora seja possivel conceber processos artificiais de solução de problemas sem que se tenha prévia compreensão de como funciona o processo natural).

Mesmo dentro dessas limitações, a automação da tomada de decisões não-programadas é, sob certos aspectos, factivel e pode apresentar dois tipos de conseqüência:

a) conduzir à automação de algumas tarefas de resolução de problemas administrativos;

b) dar meios para aumentar substancialmente a eficiência do ser humano na execução de tais tarefas. $\left({ }^{\star \star}\right)$

A automação, qualquer que seja o seu futuro desenvolvimento, terá sempre o papel de auxiliar o próprio processo humano de pensar e, conseqüentemente, concorrerá para o contínuo aperfeiçoamento dos processos de decisão não-estruturada a cargo dos cérebros humanos.

Nesse sentido, reportamo-nos às tranqüilizadoras perspectivas entrevistas por Simon:

"Seremos capazes de fazer o diagnóstico, com grande exatidão, das dificuldades do solucionador do problema específico ou do tomador de decisões, em determinado setor, e também de auxiliá-lo a modificar de certa maneira a estratégia de solucionar problemas. Seremos capazes de especificar exatamente o que é que um homem deve aprender a respeito de determinado assunto.

(*) "A Capacidade de Decisão e Liderança", obra já citada, pág. 37.

$\left(^{\star \star}\right)$ "A Capacidade de Decisão e Liderança", obra já citada, pág. 53. 
"Não temos ainda experiência que nos permita julgar que melhoramento na tomada de decisão pelo homem poderiamos esperar da aplicação dêste nôvo e crescente conhecimento a respeito dos processos de pensar à prática do ensino, à supervisão e planejamento de organizações. Não obstante, temos motivos, pensamos, para confiar no futuro". ( $\left.{ }^{*}\right)$

\section{Seção II - Modificações nas Organizações}

O conteúdo dos capitulos anteriores nos sugere a tentativa de formular um resumo de previsões sôbre futuras modificações que provàvelmente sofrerão as organizações em consequiência da evolução da tecnologia da tomada de decisão, socorrendo-nos, inclusive, de subsidios que colhemos na bibliografia em que fundamentamos êste estudo.

\section{a) Dimensão das Organizações}

Em consequiência de sua expansão (programas e diversificação da produção vertical e horizontal), as organizações futuras de grandes dimensões (como prenunciam algumas das já existentes) assumirão predominância. Essa tendência decorre, sobretudo, de exigirem as novas tecnologias maiores recursos financeiros (inclusive para o custeio de maior especialização, ampliação de conhecimentos e intensificação de pesquisa).

\section{b) Direção de Nivel Superior das Organizações}

A direção das grandes organizações será exercida, de forma colegiada, por numeroso grupo de especialistas, capazes de colaborar na tomada de decisões complexas, para as quais serão exigiveis múltiplos conhecimentos, bem como na coordenação geral das atividades organizacionais.

Esses dirigentes, dadas suas altas qualificações nas respectivas especializações, constituirão verdadeiro brain trust, sem diferenciações sensiveis de posições hierárquicas. A direção individual talvez se mantenha, simbòlicamente, com funções mais ou menos nominais.

Ao grupo dirigente assim constituido caberão as funções de programação da organização, pesquisa e tomada de macro-decisões, não previsiveis e não programáveis, insuscetiveis, pois, de resolução pelos computadores eletrônicos.

(*) Idem, págss. 55/56. 
A direção dessas grandes organizações funcionará, assim, de acôrdo com o principio de exceção de Taylor, o que mais uma vez aproxima o modêlo decisório do racionalismo do movimento de administração científica.

\section{c) Direção de Nivel Médio das Organizações}

As informações e as decisões fluirão mais fàcilmente entre a base e o tôpo das organizações. A especialização do pessoal terá prevalência sôbre a administração média. A automação suprirá muitas das funções exercidas atualmente nos níveis médios da hierarquia. Haverá, em conseqüência, numèricamente, menor necessidade de chefes de nivel médio.

\section{d) Centralização das Decisões}

A conjugação das alineas anteriores nos permite prever que a estruturação do sistema de tomada de decisão será futuramente cada vez mais centralizada. Esta conclusão também se harmoniza com a observação teórica de Simon e March no sentido de que se verifica, geralmente, nas organizações um considerável grau de paralelismo das relações hierárquicas entre os membros da organização e os elementos dos programas, isto é, os programas dos ocupantes de niveis mais altos têm como principal produto a modificação ou geração de programas para o pessoal de nivel mais baixo. $\left({ }^{*}\right)$

\section{e) Perfil Ocupacional}

Considerada a integração dos aspectos tecnológicos e econômicos da automação, é lícito fazer algumas predições sôbre o teor das atividades dos membros das organizações.

O homem conservará maior vantagem comparativa nos trabalhos que exijam manipulação flexivel de setores do ambiente relativamente grosseiros - algumas formas do trabalho manual, contrôle de alguns tipos de maquinaria (por exemplo, a operação do equipamento da movimentação de terra); alguns tipos de soIução de problemas não programados; alguns tipos de prestação de serviços em que a relação humana face a face seja essencial.

Em caráter geral, o homem se preocupará menos com a execução do trabalho diário da organização e mais com a manutenção do sistema que executa.

(*) "Teoria das Organizações", obra já citada, pág. 168. 
A intervenção tomará assim mais e mais a forma de estruturação do próprio sistema - a programação - e cada vez menos a forma de participação na operação.

A conseqüência mais evidente da automação é ter liberado grande massa de pessoas de incumbências rotineiras da produção; em conseqüência, as pessoas são, em menor número, produtores diretos e, em maior número, facilitadores. $\left({ }^{*}\right)$

\section{f) Estrututa das Organizações}

Ao invés de assemelhar-se à pirâmide, a organização do futuro parecerá mais um retângulo. Comparativamente à configuração tradicional, terá maior número de pessoas no alto, menos na base e menor número de camadas intermediárias.

Leavitt e Whisler sugeriram a perspectiva seguinte, quer intriga bastante. Inclinam-se a pensar que o abismo entre a cúpula e o fundo se tornará tão pronunciado que venha a refletir-se na estrutura. Parece que a cúpula vai à deriva, mostrando-se um tanto amorfa, enquanto o fundo é mais piramidal do que nunca. Acreditam que o diagrama do futuro deverá assemelhar-se um pouco a uma "bola equilibrada na ponta de cima de um sino de igreja." Claro que a bola é a administração de cúpula e ai a autonomia individual, a tomada de decisões em grupo e assim outras condições cada vez mais se salientarão intensamente. Espera-se que venham a ser encaradas bastante independentemente do corpo do sino da companhia, dispondo de processos de remuneração distintamente diferentes, bem como de meios de comunicação e contrôle distintos. $\left({ }^{* *}\right)$

A descentralização, baseada em grande parte no modêlo de federação, tornar-se-á cada vez mais o mein de fazer frente ao problema do tamanho das organizações. $\left({ }^{\star \star \star}\right)$

\section{g) Organizações Públicas}

A influência mais lenta da tecnologia sôbre o Serviço Público (que não opera essencialmente com a produção e não visa primacialmente a lucros) poderá retardar alterações fundamentais, paralelas às que se operarão nas organizações empresariais particulares. Certas atividades públicas já são, no entanto, afetadas pela automação e terão necessidade de enfrentar mais imediatamente problemas como a especialização de pessoal e a reformulação dos sistemas de processo decisório e de comunicações.

tiva" $\left(^{*}\right)$ PFIFFner, John, e SHERWood, Frank - "Organização Administra-

(**) Paulo, Bestseller. 1965, págs. $60 / 61,71$ e 457 .

$\left.{ }^{* *}\right)$ Idem, págs. 449 e 464 .

$\left(^{\star * \star}\right)$ "Organização Administrativa", obra já citada, pág. 449. 
A adoção de uma estratégia valorativista de reforma do Serviço Público brasileiro, que conduza à internalização de atitudes, hábitos, opiniões e estados de espírito, e à adoção de padrões comportamentais, como preconiza o Professor Kleber Nascimento $\left({ }^{*}\right)$, acarretaria, òbviamente, a plena aceitação das técnicas do processo decisório pelas organizações públicas de nosso País.

Seja-nos permitido concluir nosso estudo, sôbre a evolução do processo decisório e as organizações, sob o signo do otimismo de Simon, do qual sinceramente participamos:

"A existência atual ao mundo de máquinas que pensam e de teorias que explicam os processos do pensamento humano não subtraem uma polegada, um cabelo sequer, da estatura do. homem. O homem torna-se sempre vulnerável quando se abstém de proclamar seu valor e dignidade, e destacar aquilo em que difere do resto do mundo, ou de falar sôbre o lugar especial de que desfruta no esquema de Deus ou da natureza. $\left({ }^{* *}\right)$

\section{BIBLIOGRAFIA}

1. Simon, Herbert A., "Comportamento Administrativo." Rio de Janeiro, Fundação Getülio Vargas, 1965. Série Administração para o Desenvolvimento, $\mathrm{n}^{0} 9$.

2. March, J. G., e Simon, Herbert A. "Teoria das Organizações". Rio de Janeiro, Fundação Getúlio Vargas, 1967.

3. Simon, Herbert A. "A Capacidade de Decisão e de Liderança." Rio de Janeiro, Fundo de Cultural, 1963.

4. PriffNer, John, e SHFrwood, Frank. "Organização Administrativa." São Paulo, Bestseller, 1965.

5. Nascimento, Kleber. "Reflexões sôbre Estratégia de Reforma Administrativa: a Experiência Federal Brasileira", in Revista de Administração Pública, Fundação Getúlio Vargas, n" 1.

(*) "Reflexões sôbre Estratégia de Reforma Administrativa: a Experiência Federal Brasileira", in Revista de Administração Pública, FGV, nº 1 , pág. 48. gina 74 .

${ }^{* \star}$. . "A Capacidade de Decisão e de Liderança", obra já citada, pá-

Trabalho apresentado pelo autor, como aluno de pós-graduação do Curso de Administração, ministrado, em regime de tempo integral, pela Escola Brasileira de Administração Pública, no ano de 1967, em cumprimento ao Programa Nacional de Aperfeiçoamento de Professôres de Administração (PRONAPA), resultante de convênio celebrado entre a Fundação Getúlio Vargas e o Múnistério da Educação e Cultura. 